\title{
Practice size and service provision in primary care: an observational study
}

\author{
Claire L Morgan and Hendrik J Beerstecher
}

\begin{abstract}
Background

In 2004, primary care payments for basic services and enhanced services were separated. This change has greatly facilitated the evaluation of the breadth and volume of services.
\end{abstract}

Aim

To determine whether larger practices produce a higher volume and greater diversity of enhanced services.

\section{Design of study}

Cross-sectional observational study using practice data obtained under the Freedom of Information Act 2000.

Setting

A total of 384 practices in 14 English primary care trusts.

\section{Method}

Practice data for all practices were collated for enhanced services, practice size, and deprivation. Diversity and volume of enhanced services were used as dependent variables in a series of multiple regression models to ascertain the effect of practice size, and any relationship with deprivation.

\section{Results}

Larger practices provided a greater diversity of services $(P=0.002)$, although this effect was not present in practices with more than 6330 patients. Practice size seems to influence the volume of enhanced services in general medical services, but this effect disappeared when deprivation was taken into account. Deprivation had a negative influence on the volume of enhanced services provided $(P=0.019)$. The effect of deprivation on volume persisted in practices with more than 6330 patients.

\section{Conclusion}

Current average-sized practices provide similar volume and diversity of enhanced services as those in the largest quartile; therefore, there seems to be little merit in creating 'supersurgeries' if the aim is to transfer work from secondary to primary care. There does not seem to be an upper threshold above which practice size creates spare capacity and expertise to deliver a significantly greater volume or more diversity of extra services.

\section{Keywords}

health care reform; health facility size; primary health care; state medicine.

\section{INTRODUCTION}

It is thought that transferring care from secondary to primary care leads to a reduction of cost and improved patient convenience. ${ }^{1}$ However, even though practices might have been be able to offer additional services, UK primary care contracts preceding 2004 offered little scope to fund them. ${ }^{2}$ Primary care in the UK is mainly funded on a capitation basis; therefore, transfer of work from secondary care is not accompanied by funding and there is no incentive for practices to take extra work on. In 1996 the British Medical Association suggested that separating 'core' and 'non-core' services could create the flexibility to fund practices that wanted to offer additional services. ${ }^{3}$ The 2004 general medical services (GMS) contract introduced this structure by separating essential services from additional and enhanced services.

Corrigan proposed that very large primary care practices (practices with a large practice population) could provide a greater range and volume of services due to a reduction of limitations of infrastructure and equipment. ${ }^{4}$ This theory is attractive and seems to be supported anecdotally by the authors' experience in a small practice with fewer than 2000 patients. For example, this practice declined to take up coumarin dosing, as training and developing a fail-safe system would be needed to match the well-established, well-run secondary care service already in place. Even if start-up costs were ignored, providing an effective

CL Morgan, BA (Hons), senior researcher; HJ Beerstecher, GP principal, Canterbury Road Surgery, Sittingbourne, Kent.

Address for correspondence

Hendrik J Beerstecher, Canterbury Road Surgery,

111 Canterbury Road, Sittingbourne, Kent, ME10 4JA.

E-mail: hendrick.beerstecher@nhs.net

Submitted: 28 June 2008; Editor's response: 19 August 2008; final acceptance: 15 October 2008.

(OBritish Journal of General Practice

This is the full-length article of an abridged version published in print. Cite this article as: $\mathrm{Br} J$ Gen Pract 2009; DOI: 10.3399/bjgp09X419538 
service for 17 patients was also not economically viable due to the audit and service requirements associated with this enhanced service. In a larger practice, one of the physicians or nurses may be able to acquire the necessary expertise to deliver a high-quality, clinically safe service. ${ }^{5}$ The current authors were denied the opportunity to offer an enhanced service for chronic pulmonary disease as it was thought that the equipment lacked the sophistication of that of the primary care trust (PCT) clinic. Again, the cost of the equipment and the low number of eligible patients would have meant running the service at a loss for 5 years before breaking even.

The main intention of enhanced services is to enable PCTs to reduce demand on secondary care by transferring clinical activity to primary care. ${ }^{6}$ Previous studies have not demonstrated that such a policy is effective for minor surgery or diabetes care. ${ }^{7,8} \mathrm{~A}$ new aspect of enhanced services is that secondary care work generated or declined by one primary care provider can be transferred to another primary care provider. The question is whether large practices generate the extra capacity needed to transfer this work to primary care.

The structure of the 2004 GMS contract, where extra services are specified and are paid separately, is well suited for analysis of the relationship between practice size and extra services. This report examines whether large primary care practices deliver a higher volume and greater diversity of these services.

\section{METHOD}

\section{Practices}

Enhanced services data on 384 practices in 14 PCTs were collated. The PCTs included were: Bassetlaw $(n=12)$, Bedford $(n=25)$, Bristol $(n=$ $58)$, Calderdale $(n=29)$, Canterbury $(n=20)$, Exeter ( $n=19)$, Mendip $(n=13)$, Milton Keynes $(n=27)$, Northamptonshire $(n=82)$, Poole $(n=20)$, South Gloucestershire $(n=29)$, Taunton $(n=15)$, West Hertfordshire $(n=21)$, and Wokingham $(n=14)$.

These PCTs were chosen for the presence of especially large practices (at least one practice with $>15000$ patients) or three or more large practices (>10 000 patients). Appendices 1 and 2 show PCT characteristics and how the sample compares to all English practices.

\section{Enhanced services}

There are three categories of enhanced services: designated enhanced services (DESs), national enhanced services (NESs), and local enhanced services (LESs). Although the PCTs have an obligation to commission DESs for all patients, and

\section{How this fits in}

Larger practices are thought to provide a greater volume and diversity of services, but there is no study confirming this. While very small practices provide less diversity and volume of services, there is little difference in enhanced service provision between average-sized practices and

'supersurgeries'. Any variation that does exist is associated, to a certain extent, with deprivation. Larger practices do not provide a greater volume of extra services after accounting for deprivation. Therefore, a policy to create larger practices may not automatically lead to a transfer of work from secondary to primary care.

the practice is generally offered first refusal, there is no obligation for a practice to take up any enhanced service. The NESs are services with nationally uniform specifications and payments, while the LESs have specifications and payments determined by the local PCT. For NESs and LESs there is no obligation on the PCT to commission services, and the quantity and variety of options available to practices varies from place to place.

Enhanced services are paid separately from other funding sources and are therefore easily identifiable. Practice payment data were requested for enhanced services between 2005 and 2007.

The total payment for all enhanced services provided by each individual practice was divided by the practice size (number of registered patients), to give a measure of the volume of enhanced services provided. Volume represents income generated and is therefore displayed in $£$ per patient per annum.

The diversity of enhanced services was derived from the number of different enhanced services provided by each practice.

\section{Deprivation}

The Index of Multiple Deprivation (IMD) was used, based on the demographic details of the registered patients. ${ }^{9}$ This is strongly related $(r=0.81)$ to the practice postcode-based IMD, which is used in many other studies, but it reflects more closely the composition of the practice population. ${ }^{10}$ The score for the least-deprived English practice is 2.16, and it is 81.89 for the most-deprived practice. Figures for patient-based IMD score were available for 365 of the practices studied (95\%).

Overall, the practices included in the study had more-affluent populations than the English average (mean IMD score 17.51 versus 23.31). PCT-level data indicated the selected PCTs had varying degrees of deprivation, although large practices were over-represented in affluent areas.

\section{Statistical methods}

Analysis was performed on the study group as a 
whole and by contract status, GMS and personal medical services (PMS), as initial descriptive statistics revealed PMS practices to be larger and looking after relatively more-deprived populations (Appendix 3). The differences may exist as only GMS contracts with perceived local problems, often related to deprivation or recruitment, were replaced by PMS.11

GMS $(n=178)$ and PMS $(n=206)$ practices were grouped into quartiles according to practice size (descriptive data, Appendix 4). One-way analysis of variance (ANOVA) was performed to compare the practice volume (income generated by enhanced services per patient per annum) and diversity (number of enhanced services provided). Where ANOVA indicated a significant group effect, post hoc pairwise testing with Tukey's HSD ('honestly significantly different') test was performed.

Regression analyses using multilevel models clustered by PCT were run with contract status, practice size, and deprivation as predictor variables for volume and diversity. Additional multiple regression models were designed to discover whether large practices provide greater volume and diversity of enhanced services than practices serving an average population (6330 patients in 2006). ${ }^{12}$

\section{RESULTS}

\section{Volume of enhanced services}

For GMS practices, the volume of enhanced services varied with practice size $(\mathrm{F}(3,174)=3.31, P$ $=0.02)$. Post hoc tests revealed significant differences between practices in the first and third $(P<0.05)$, and first and fourth quartiles $(P<0.05)$. By contrast, the volume of enhanced services provided by $\mathrm{PMS}$ practices did not differ between quartiles $(\mathrm{F}(3,202)=1.58, P=0.20)$.

A multiple regression model was run on all practices. Data were clustered by PCT to take local effects into account. The dependent variable was the volume of enhanced services, with contract status, practice size, and deprivation as predictor variables. The model predicted $9 \%$ of the variation in the volume of services provided, although only deprivation reached significance $(P=0.019$; model outlines in Appendix 5).

As practice size appeared to be relevant to the volume of enhanced services in the analysis on quartiles but did not reach significance in the multiple regression for all practices, separate regressions were also run for practices larger and smaller than the average English list size. These models demonstrated that practice size is not significantly influential for the volume of enhanced services when deprivation is taken into account (Table 1).

Two further multiple regression models were run to analyse GMS and PMS practices separately. Practice size and deprivation were entered as predictor variables. Analysis of GMS practices with clustering for PCT demonstrated that practice size and deprivation explain $13 \%$ of the variation in the volume of services provided, but neither variable reached significance. The PMS model indicated deprivation as a significant predictor for the volume of enhanced services $(P=0.024)$, suggesting that the effect seen in the combined model was mainly due to practices working under PMS contracts (Appendix 5).

Table 1. Multiple regression analyses, separated by mean practice size (clustered by primary care trust).

\begin{tabular}{|c|c|c|c|}
\hline & $\begin{array}{l}\text { Unstandardised } \\
\text { regression coefficient }(95 \% \mathrm{Cl})\end{array}$ & $\begin{array}{l}\text { Standardised } \\
\text { regression coefficient }\end{array}$ & $P$-value \\
\hline \multicolumn{4}{|c|}{ Volume of enhanced services (all practices with list size $\geq 6330, n=217$ ) } \\
\hline Contract status & $0.8012(-1.6554$ to 3.2575$)$ & 0.098 & 0.494 \\
\hline Practice size & $0.00001(-0.0001$ to 0.0001$)$ & 0.009 & 0.840 \\
\hline Deprivation & $-0.0938(-0.1802$ to -0.0074$)$ & -0.189 & 0.036 \\
\hline \multicolumn{4}{|c|}{ Volume of enhanced services (all practices with list size $<6330, n=148$ ) } \\
\hline Contract status & $1.1252(-0.3783$ to 2.6287$)$ & 0.124 & 0.130 \\
\hline Practice size & $0.0005(-0.0002$ to 0.0012$)$ & 0.164 & 0.126 \\
\hline Deprivation & $-0.1569(-0.2577$ to -0.0561$)$ & -0.344 & 0.005 \\
\hline \multicolumn{4}{|c|}{ Diversity of enhanced services (all practices with list size $\geq 6330, n=217$ ) } \\
\hline Contract status & $-1.1977(-2.955$ to 0.5599$)$ & -0.270 & 0.165 \\
\hline Practice size & $0.0001(-0.0000$ to 0.0002$)$ & 0.148 & 0.142 \\
\hline Deprivation & $-0.0324(-0.1147$ to 0.0499$)$ & -0.120 & 0.411 \\
\hline \multicolumn{4}{|c|}{ Diversity of enhanced services (all practices with list size $<6330, n=148$ ) } \\
\hline Contract status & $-0.3472(-1.8746$ to 1.1801$)$ & -0.070 & 0.632 \\
\hline Practice size & 0.0005 (0.0001 to 0.0009$)$ & 0.281 & 0.019 \\
\hline Deprivation & $-0.0754(-0.1444$ to -0.0064$)$ & -0.300 & 0.035 \\
\hline
\end{tabular}




\section{Diversity of enhanced services}

As with volume, the diversity of enhanced services provided by GMS practices also varied with practice size $(\mathrm{F}(3,174)=14.23, P<0.001)$. Post hoc tests revealed that the significant differences were between the first and each of the other three quartiles $(P<0.01)$. Practice size was also important for PMS practices when looking at diversity $(F(3,202)=3.52, P=0.02)$, with post hoc tests showing significant differences between the first and fourth quartile $(P<0.01)$.

Multiple regression analysis on the diversity of enhanced services for all practices clustered by PCT revealed that contract status, practice size, and deprivation account for $16 \%$ of the variation, although only practice size was a significant predictor for diversity $(P=0.002)$. Separate regression models for GMS and PMS practices revealed that practice size is a significant predictor for diversity for both contract types (GMS: $P=$ 0.013; PMS: $P=0.023$; Appendix 5).

Despite the significant relationship between practice size and diversity, multiple regression analysis of all practices with greater than or equal to, and those with less than the average English list size, demonstrated that the diversity of enhanced services does not continue to increase with practice size >6330 patients (Table 1). Practice size only appears to be important for the diversity of services provided by practices with lists of fewer patients than the national average, which is in keeping with the ANOVA results.

\section{Deprivation}

Deprivation varied with practice size in both GMS and PMS groups. For GMS practices $(F(3,165)=$ $4.60, P=0.004)$ there were significant differences between the first and third $(P<0.01)$ and first and fourth quartiles $(P<0.05)$. In PMS practices, similar trends were observed $(F(3,192)=3.47, P=0.02)$, with differences again between the smallest (first quartile) and largest (fourth quartile) practice size groups $(P<0.05)$.

\section{DISCUSSION}

\section{Summary of main findings}

While small practices provide less diversity of enhanced services, there is no evidence in the present study group to suggest that very large practices are providing more volume or diversity than the current average English practice.

There is a long-standing perception that larger practices have the capacity to provide a greater volume and diversity of services, which may explain the current trend towards encouraging larger practices. ${ }^{13-15}$ It would also be reasonable to assume that PMS practices provide more enhanced services, as PMS contracts were designed to meet local needs and improve the quality of service delivery. ${ }^{11}$

The present findings question the validity of these assumptions. The diversity of enhanced services is only less when small PMS practices in the smallest quartile ( $\leq 5428$ patients) are compared to PMS practices in the largest quartile ( $\geq 11570$ patients), but the volume of enhanced services in PMS practices is not related to practice size.

The picture in GMS is slightly different. Small GMS practices ( $\leq 4104$ patients) provide less diversity and volume than GMS practices in the third and fourth quartiles ( $\geq 6535$ patients). However, when studying practices of average size or larger, there is very little difference in service provision between the current average English practice size (6330 patients) and 'supersurgeries' catering for upwards of 30000 patients.

Although the study's $t$-tests indicate that there are differences between GMS and PMS in volume and diversity, these are small in real terms. This is supported by the regression models, which show contract status does not predict the volume or diversity of enhanced services.

\section{Strengths and limitations of the study}

PCTs with large practices were purposively sampled, as random sampling could not guarantee to yield sufficient large practices for study. A disadvantage of this is that practice size may be related to other practice characteristics. It is known, for instance, that larger practices serve areas of lower deprivation and the other practices in the PCT are therefore also likely to serve more-affluent patients. Therefore the present findings cannot be translated unreservedly to the whole of the UK. It could be that areas with larger practices were offered systematically more or fewer enhanced services by their PCT, or that the uptake of enhanced services is systematically lower or higher in these areas.

An advantage of sampling whole PCTs is that the practices are automatically compared to their peers, with smaller practices serving a similar population. It is likely that the same enhanced services were, in principle, available to smaller and larger practices within each PCT. Therefore, any differences found between large and small practices are unlikely to be due to availability of options or to differences in practice population.

\section{Comparison with existing literature}

Ashworth et al suggested that the provision of extra services might not be very profitable. ${ }^{16}$ Profitability 
may therefore not be one of the major considerations when practices decide to take on enhanced services. However, the present study looked at income generation, and as larger practices provide a greater number of services, they should earn more money from them. This is not borne out by the present models, which show practice size is not a predictor for volume (income generated by enhanced services per patient per annum).

This discrepancy between diversity and volume could have two explanations. Firstly it is possible that some services generate little income, and the study was unable to detect a difference in volume where a difference in diversity was found. Secondly, it could be that there is a ceiling on capacity and that generating income from one further enhanced service reduces the income gained from the others.

Deprivation is associated with a reduced volume of services and this relationship persists even for larger-than-average practices. This finding could indicate that deprivation-related workload impinges on the capacity to deliver significant volumes of extra services, even among very large practices. That would also suggest that spare capacity is finite and is not generated as practices get larger.

\section{Implications for clinical practice}

There seems to be little merit in creating 'supersurgeries' if the aim is to transfer work from secondary to primary care. Current average-sized practices provide a similar volume and diversity of enhanced services to their large neighbours, and there does not seem to be an upper threshold above which practice size creates the spare capacity or expertise to enable delivery of significantly more or greater diversity of extra services.

\section{Ethical approval}

The study was performed with publicly available data, which do not relate to individuals, and the Kent Ethical Committee confirmed that no approval was necessary for this project

\section{Competing interests}

The authors have stated that there are none

\section{Acknowledgements}

We thank the PCT FOI officers for providing the data free of charge. We are grateful for the free provision of the practicebased Index of Multiple Deprivation by Dr Mark Ashworth and $\mathrm{Mr}$ Stevo Durbaba, and the to Department of Health for publishing the patient-based IMD. We thank family and friends for tolerating and supporting us in the last 4 years.

\section{Discuss this article}

Contribute and read comments about this article on the Discussion Forum: http://www.rcgp.org.uk/bjgp-discuss

\section{REFERENCES}

1. Department of Health. Implementing care closer to home: convenient quality care for patients. Part 1: Introduction and overview. London: Department of Health, 2007.

http://www.dh.gov.uk/prod_consum_dh/idcplg?IdcService=GET_F ILE\&dID=139326\&Rendition=Web (accessed 13 Feb 2009).

2. Jewell D. Supporting diversity in primary care. BMJ 1997; 314(7096): 1706

http://www.bmj.com/cgi/content/full/314/7096/1706 (accessed 13 Feb 2009).

3. Pedersen L, Leese B. What will a primary care led NHS mean for GP workload? The problem of the lack of an evidence base. BMJ 1997; 314(7090): 1337.

http://www.bmj.com/cgi/content/full/314/7090/1337 (accessed 13 Feb 2009).

4. Corrigan P. Size matters: making GP services fit for purpose. London: The New Health Network, 2005.

http://www.newhealthnetwork.co.uk/Documents/Event/size_matte rs_v3.pdf (accessed 13 Feb 2009).

5. Department of Health. Practitioners with special interests. London: Department of Health, 2007.

http://www.dh.gov.uk/en/Policyandguidance/Organisationpolicy/P rimarycare/Practitionerswithspecialinterests/index.htm (accessed 13 Feb 2009).

6. Department of Health. Enhanced services. London: Department of Health, 2007.

http://www.dh.gov.uk/en/Healthcare/Primarycare/PrimaryCareCo ntracting/DH_4126088 (accessed 13 Feb 2009).

7. Goyder EC, McNally PG, Drucquer M, et al. Shifting of care for diabetes from secondary to primary care, 1990-5: review of general practices. BMJ 1998; 316(7143): 1505-1506. http://www.bmj.com/cgi/content/full/316/7143/1505 (accessed 13 Feb 2009).

8. Lowy A, Brazier J, Fall M, et al. Minor surgery by general practitioners under the 1990 contract: effect on hospital workload. $B M J$ 1993; 307(6901): 413-417.

http://www.pubmedcentral.nih.gov/picrender.fcgi?artid=1678425\& blobtype $=$ pdf (accessed 13 Feb 2009).

9. Department of Health. GP patient surveys: your doctor, your experience, your say. London: Department of Health, 2007. http://www.dh.gov.uk/en/Publicationsandstatistics/PublishedSurve $\mathrm{y} /$ GPpatientsurvey $2007 /$ index.htm?IdcService=GET_FILE\&dID=1 44856\&Rendition=Web (accessed 13 Feb 2009). [Note, this links to a large (8M) Excel file. The IMD is in column CX.]

10. McLean G, Guthrie B, Watt G, et al. Practice postcode versus patient population: a comparison of data sources in England and Scotland. Int J Health Geogr 2008, 7: 37. http://www.ijhealthgeographics.com/content/7/1/37 (accessed 13 Feb 2009).

11. The PMS National Evaluation Team. National evaluation of first wave NHS personal medical services pilots. London: Department of Health, 2002.

http://www.dh.gov.uk/prod_consum_dh/groups/dh_digitalassets/ @dh/@en/documents/digitalasset/dh_4118852.pdf (accessed 13 Feb 2009).

12. The NHS Information Commissioner. QOF 2005/06 detailed spreadsheets. NHS: London. September 2006. http://www.ic.nhs.uk/statistics-and-data-collections/supportinginformation/audits-and-performance/the-quality-and-outcomesframework/qof-2005/06/qof-2005-06-detailed-spreadsheets (accessed 13 Feb 2009).

13. Bosanquet N, Leese B. Family doctors and innovation in general practice. BMJ 1988; 296(6636): 1576-1580. http://www.pubmedcentral.nih.gov/picrender.fcgi?artid=2545960\& blobtype $=$ pdf (accessed 13 Feb 2009).

14. Baker R. General practice in Gloucestershire, Avon and Somerset: explaining variations in standards. Br J Gen Pract 1992, 42(363): $415-418$.

http://www.pubmedcentral.nih.gov/picrender.fcgi?artid=1372231\& blobtype $=$ pdf (accessed 13 Feb 2009).

15. Majeed A. The future of singlehanded general practices. BMJ 2005; 330(7506): 1460-1461.

http://www.bmj.com/cgi/content/full/330/7506/1460 (accessed 13 Feb 2009).

16. Ashworth M, Armstrong D, de Freitas J, et al. The relationship between income and performance indicators in general practice. Health Serv Manage Res 2005; 18: 258-264. http://hsmr.rsmjournals.com/cgi/content/abstract/18/4/258 (accessed 13 Feb 2009). 
Appendix 1. Primary care trust (PCT) characteristics.

\begin{tabular}{lcccc} 
PCT & $\begin{array}{c}\text { Number of practices in PCT } \\
\text { with list size } 10 \text { 000-14 999 }\end{array}$ & $\begin{array}{c}\text { Number of practices in } \\
\text { PCT with list size }>15 \text { 000 }\end{array}$ & $\begin{array}{c}\text { List size range } \\
\text { across PCT }\end{array}$ & Average IMD score \\
\hline Bassetlaw & 1 & 2 & 1446 to 33438 & 23.91 \\
\hline Bedfordshire & 4 & 1 & 1212 to 15421 & 16.78 \\
\hline Bristol & 12 & 2 & 1383 to 21578 & 26.56 \\
\hline Calderdale & 8 & 1 & 1697 to 18453 & 26.91 \\
\hline Canterbury & 6 & 2 & 1809 to 31626 & 15.57 \\
\hline Exeter & 0 & 1 & 2018 to 29633 & 19.89 \\
\hline Mendip & 2 & 1 & 1868 to 28188 & 13.60 \\
\hline Milton Keynes & 10 & 1 & 3091 to 15718 & 15.73 \\
\hline Northamptonshire & 22 & 6 & 1370 to 20757 & 15.00 \\
\hline Poole & 3 & 2 & 1575 to 29823 & 14.62 \\
\hline South Gloucestershire & 14 & 0 & 1095 to 14063 & 10.15 \\
\hline Taunton & 3 & 1 & 2942 to 15238 & 15.53 \\
\hline West Hertfordshire & 8 & 1 & 2074 to 17080 & 12.19 \\
\hline Wokingham & 4 & 3 & 1531 to 26082 & 5.78 \\
\hline
\end{tabular}

IMD = Index of Multiple Deprivation

Appendix 2. Study group characteristics compared with all English practices (data from 2006). ${ }^{12}$

\begin{tabular}{lccc} 
& List size $\geq 10000(\%)$ & List size range & Average IMD score \\
\hline Study group & 32 & 1095 to 33438 & 17.51 \\
\hline All English practices & 17 & 63 to 36493 & 23.31 \\
\hline
\end{tabular}

$I M D=$ Index of Multiple Deprivation

Appendix 3. $t$-tests showing differences between general medical services (GMS) and personal medical services (PMS) practices in study group.

\begin{tabular}{|c|c|c|c|c|c|}
\hline & $n$ & List size & IMD score ${ }^{a}$ & $\begin{array}{c}\text { Volume of enhanced } \\
\text { services }{ }^{b}, £\end{array}$ & $\begin{array}{l}\text { Diversity of } \\
\text { services }^{\circ}\end{array}$ \\
\hline GMS & 178 & $\begin{array}{c}7296.74 \\
\text { (6681.46 to } 7910.02)\end{array}$ & $\begin{array}{c}15.67 \\
\text { (4.53 to } 16.81)\end{array}$ & $\begin{array}{c}10.56 \\
\text { (9.98 to } 11.14)\end{array}$ & $\begin{array}{c}10.02 \\
\text { (9.66 to } 10.38)\end{array}$ \\
\hline PMS & 206 & $\begin{array}{c}8940.29 \\
\text { (8197.14 to } 9683.43)\end{array}$ & $\begin{array}{c}19.11 \\
\text { (17.74 to } 20.48)\end{array}$ & $\begin{array}{c}11.42 \\
\text { (10.80 to } 12.04)\end{array}$ & $\begin{array}{c}9.42 \\
\text { (9.09 to } 9.75)\end{array}$ \\
\hline$t$-test & & $-3.30^{d}$ & $-3.73^{d}$ & $-1.98^{\circ}$ & $2.39^{\circ}$ \\
\hline
\end{tabular}

$95 \%$ confidence interval in brackets. ${ }^{\mathrm{a}}$ Mean Index of Multiple Deprivation (IMD) score (higher score = greater deprivation). ${ }^{\circ} \mathrm{Mean}$ volume of enhanced services displayed in $£$ per patient per year. ${ }^{\circ}$ Mean number of enhanced services provided. ${ }^{d} P<0.01 .{ }^{\circ} P<0.05$. 
Appendix 4. Descriptive data of quartiles used for one-way ANOVA.

\begin{tabular}{|c|c|c|c|c|}
\hline GMS & $\begin{array}{l}\text { Quartile } 1 \\
(n=44)\end{array}$ & $\begin{array}{c}\text { Quartile } 2 \\
(n=44)\end{array}$ & $\begin{array}{c}\text { Quartile } 3 \\
(n=45)\end{array}$ & $\begin{array}{c}\text { Quartile } 4 \\
(n=45)\end{array}$ \\
\hline List size & $\begin{array}{c}2743 \\
\text { (1095 to } 4104)\end{array}$ & $\begin{array}{c}5336 \\
\text { (4185 to } 6510)\end{array}$ & $\begin{array}{c}8104 \\
\text { (6535 to } 9951)\end{array}$ & $\begin{array}{c}12855 \\
\text { (9979 to } 26 \text { 082) }\end{array}$ \\
\hline Volume, $£$ & $\begin{array}{c}9.02 \\
(0.00 \text { to } 19.87)\end{array}$ & $\begin{array}{c}10.77 \\
\text { (2.54 to } 21.86)\end{array}$ & $\begin{array}{c}11.29 \\
(5.10 \text { to } 19.99)\end{array}$ & $\begin{array}{c}11.14 \\
\text { (5.06 to } 23.76)\end{array}$ \\
\hline Diversity & $\begin{array}{c}8.27 \\
(0 \text { to } 14)\end{array}$ & $\begin{array}{c}9.91 \\
\text { (5 to } 14)\end{array}$ & $\begin{array}{c}10.84 \\
(8 \text { to } 14)\end{array}$ & $\begin{array}{c}11.00 \\
(7 \text { to } 16)\end{array}$ \\
\hline PMS & $\begin{array}{l}\text { Quartile } 1 \\
(n=51)\end{array}$ & $\begin{array}{c}\text { Quartile } 2 \\
(n=51)\end{array}$ & $\begin{array}{c}\text { Quartile 3 } \\
(n=52)\end{array}$ & $\begin{array}{c}\text { Quartile } 4 \\
(n=52)\end{array}$ \\
\hline List size & $\begin{array}{c}3401 \\
(1383 \text { to } 5248)\end{array}$ & $\begin{array}{c}6647 \\
\text { (5255 to } 7855)\end{array}$ & $\begin{array}{c}9824 \\
\text { (7909 to } 11568)\end{array}$ & $\begin{array}{c}15738 \\
\text { (11 } 570 \text { to } 33438)\end{array}$ \\
\hline Volume, $£$ & $\begin{array}{c}10.52 \\
\text { (2.15 to } 22.06)\end{array}$ & $\begin{array}{c}10.99 \\
\text { (5.49 to 19.19) }\end{array}$ & $\begin{array}{c}11.98 \\
\text { (4.28 to } 31.32)\end{array}$ & $\begin{array}{c}12.16 \\
\text { (4.26 to } 20.72)\end{array}$ \\
\hline Diversity & $\begin{array}{c}8.61 \\
\text { (3 to 15) }\end{array}$ & $\begin{array}{c}9.45 \\
\text { (7 to } 14)\end{array}$ & $\begin{array}{c}9.50 \\
(6 \text { to } 14)\end{array}$ & $\begin{array}{c}11.12 \\
(6 \text { to } 19)\end{array}$ \\
\hline
\end{tabular}

Range of values shown in brackets. GMS = General Medical Services. PMS = Personal Medical Services.

Appendix 5. Multiple regression analyses, predictors for volume and diversity of enhanced services, all models clustered by primary care trust.

\begin{tabular}{lccc} 
& $\begin{array}{c}\text { Unstandardised regression } \\
\text { coefficient }(95 \% \text { Cl) }\end{array}$ & $\begin{array}{c}\text { Standardised } \\
\text { regression coefficient }\end{array}$ & $P$-value \\
\hline Volume of enhanced services & & & \\
\hline All practices $(n=365)$ & $0.9701(-0.9108$ to 2.8510$)$ & 0.114 & 0.285 \\
$\quad$ Contract status & $0.0001(-0.0000$ to 0.0002$)$ & 0.086 & 0.122 \\
Practice size & $-0.1282(-0.2318$ to -0.0246$)$ & -0.270 & 0.019 \\
Deprivation & & & \\
\hline GMS practices $(n=169)$ & $0.0001(-0.0001$ to 0.0003$)$ & 0.066 & 0.506 \\
Practice size & $-0.1749(-0.3541$ to 0.0043$)$ & -0.342 & 0.055 \\
Deprivation & & & \\
\hline PMS practices $(n=196)$ & $0.0001(-0.0000$ to 0.0002$)$ & 0.093 & 0.069 \\
Practice size & $-0.1044(-0.1919$ to -0.01691$)$ & -0.223 & 0.024 \\
\hline Deprivation & & & \\
\hline Diversity of enhanced services & & & \\
\hline All practices $(n=365)$ & $-0.8117(-2.4233$ to 0.8000$)$ & -0.170 & 0.296 \\
Contract status & $0.0001(0.0001$ to 0.0002$)$ & 0.277 & 0.002 \\
Practice size & $-0.0570(-0.1227$ to 0.0087$)$ & -0.213 & 0.084 \\
Deprivation & & & \\
\hline GMS practices $(n=169)$ & $0.0002(0.0000$ to 0.0003$)$ & 0.310 & 0.013 \\
Practice size & $-0.0838(-0.1957$ to 0.0282$)$ & -0.271 & 0.129 \\
Deprivation & & & \\
\hline PMS practices $(n=196)$ & $0.0001(0.0000$ to 0.0002$)$ & 0.260 & 0.023 \\
Practice size & $-0.0424(-0.1029$ to 0.0182$)$ & -0.173 & 0.150 \\
Deprivation & & & \\
\hline
\end{tabular}

GMS $=$ General Medical Services. PMS $=$ Personal Medical Services. 